Note

\title{
Primary Malignant Hepatic Glucagonoma: An Autopsy Case
}

\author{
NAOKo OBI*, TAKUYUki KATABAMI*, RyUSei OBI*, Mieko ODANAKA**, KiminOBU SASANO*** \\ AND YASUSHI TANAKA* \\ *Division of Metabolism and Endocrinology, St. Marianna University School of Medicine, Kanagawa, Japan \\ ** Division of Pathology, Department of Internal Medicine, St. Marianna University School of Medicine, Kanagawa, Japan \\ ${ }^{* * *}$ Department of Pathology, Medical School, Tohoku University, Sendai, Japan
}

\begin{abstract}
A 73-year-old woman was admitted to our department for treatment of diabetes (plasma glucose $289 \mathrm{mg} / \mathrm{dl}$, $\mathrm{HbA}_{1 \mathrm{C}} 7.1 \%$, and glycated albumin $34.9 \%$ ). She displayed the signs and symptoms of glucagonoma syndrome, including necrolytic migratory erythema (NME), low aminoacidemia, and a marked increase of the serum glucagon level (4,940 pg/ $\mathrm{ml}$ ). Thus, we suspected a glucagonoma causing secondary diabetes. However, we could not detect any mass in the pancreas or the gastrointestinal tract, and only found a liver lesion resembling a hemangioma. Her NME improved markedly after intravenous infusion of amino acids, and her plasma glucose was controlled reasonably well by intensive insulin therapy. However, her general condition deteriorated and she died on day 57 after hospitalization. At autopsy, the only tumor detected was the liver mass. This was a large solid tumor $(8 \times 6 \times 5 \mathrm{~cm})$ with a pattern of white and dark brown stripes located in the left lobe, while two white nodules were also found in the right lobe. Based on the histopathological and immunohistochemical findings, the liver lesion was shown to be a malignant glucagonoma with intrahepatic metastases. Since primary malignant hepatic glucagonoma has not been reported before, we present this extremely rare case of primary malignant glucagonoma of the liver.
\end{abstract}

Key words: Neuroendocrine tumor (NET), Neuroendocrine carcinoma, Primary malignant hepatic glucagonoma

(Endocrine Journal 56: 715-719, 2009)

NEUROENDOCRINE tumors (NETs) are diagnosed on the basis of typical histological findings and the diagnosis is confirmed by diffuse positive staining for neuroendocrine cell markers [1]. NETs are not only found in endocrine glands, but can occur throughout the body, including the gastrointestinal tract, lungs, and liver. Glucagonoma is one of the NETs, and it almost always arises from the islets of the pancreas, with extrapancreatic tumors accounting for less than $1 \%$ of all cases [2]. Primary hepatic glucagonoma has not been reported before. Here we present an extremely rare case of primary malignant hepatic glucagonoma that was confirmed at autopsy.

Received Feb. 23, 2009; Accepted Apr. 1, 2009 as K09E-058 Released online in J-STAGE as advance publication Apr. 11, 2009

Correspondence to: Takuyuki KATABAMI, M.D., Division of Metabolism and Endocrinology, Department of Medicine, St. Marianna University School of Medicine, 2-16-1 Sugao, Miyamaeku, Kawasaki 216-8511, Japan.

E-mail: t2kataba@marianna-u.ac.jp

\section{Case Report}

The patient was a 73-year-old woman. At the age of 63 years, distal gastrectomy (Billroth II) was performed at another hospital, but we could not obtain any information with regard to the underlying disease. She had a history of heart failure at the age of 64 years. Since then, a liver mass had been found (suspected hemangioma) and myelodysplastic syndrome had occurred at 71 years of age. Diabetes mellitus had been diagnosed at our hospital when she was aged 69 years, but she had been followed without any anti-diabetic therapy. Since her postprandial glucose level increased to $379 \mathrm{mg} / \mathrm{dl}$, she was admitted to our ward for the treatment of diabetes when she was 73 years old.

\section{Physical examination}

On admission, she was very lean (BMI $12.0 \mathrm{~kg} / \mathrm{m}^{2}$ ). Blood pressure was normal $(116 / 89 \mathrm{mmHg})$, heart rate 


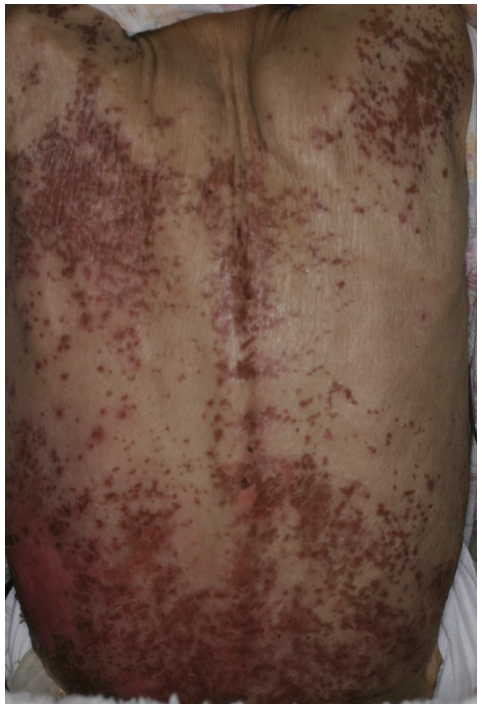

Back

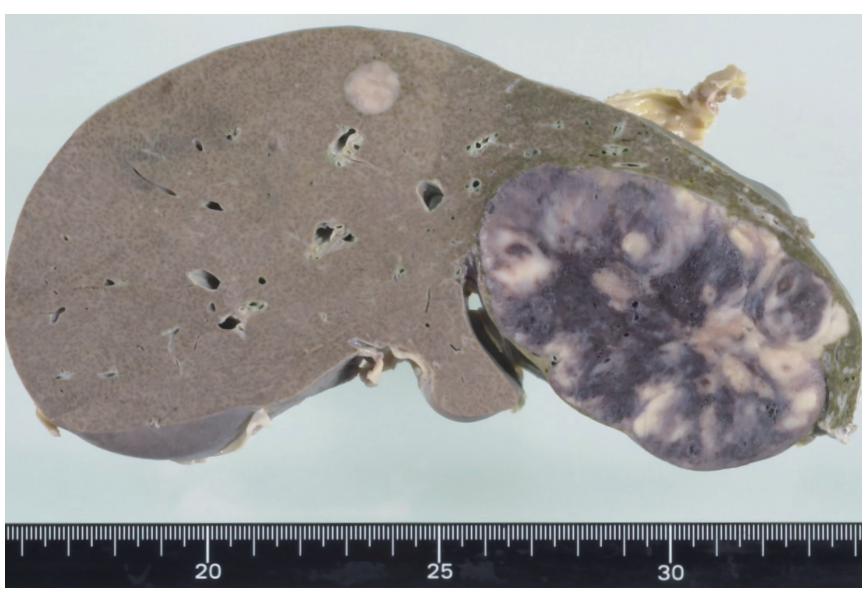

Liver

Fig. 1. Skin and gross findings.

The patient had severe erythema, ulceration, and blistering of her back, which was diagnosed as necrolytic migratory erythema (NME). At autopsy, there is a large solid mass $(8 \times 6 \times 5 \mathrm{~cm})$ with a pattern of white and dark brown stripes in the left lobe of the liver, and two white nodules $(1.2$ and $1.0 \mathrm{~cm}$ in diameter) in the right lobe.

was increased (109/min, sinus rhythm), and body temperature was $35.4^{\circ} \mathrm{C}$. Physical examination revealed no significant abnormalities, apart from severe erythema, ulceration, and blistering on the bilateral lower and upper limbs. A consultant dermatologist diagnosed necrolytic migratory erythema (NME) (Fig. 1).

\section{Laboratory and imaging findings}

As shown in Table 1, the white blood cell count, platelet count, and erythrocyte sedimentation rate (ESR) were elevated, while the red blood cell count was decreased. The plasma total protein and albumin levels were decreased, while plasma creatinine and CRP levels were increased. Hyperuricacidemia, which was mainly attributed to severe dehydration and renal dysfunction, was observed. Regarding parameters of glucose metabolism, postprandial plasma glucose (PPPG), glycated albumin (GA), and $\mathrm{HbA}_{1 \mathrm{c}}$ were all increased, while insulin and urinary c-peptide (U-CPR) were suppressed. Tumor markers were within normal range, but her plasma glucagon level was markedly increased $(4,940 \mathrm{pg} / \mathrm{ml})$. Serum amino acid analysis showed that all amino acid fractions were decreased. Abdominal ultrasonography showed a giant $(98 \times 63 \mathrm{~mm})$ isoechoic mass with a hyperechoic rim in segment (S) 2-3 of the left lobe of liver. In addition, similar nodules were present in $\mathrm{S} 7(8 \times 8 \mathrm{~mm})$ and $\mathrm{S} 8$ $(18 \times 19 \mathrm{~mm})$ of the right lobe. CT scanning revealed that these masses had a low density compared with the normal liver parenchyma, and were isoechoic with the kidney. Therefore, we suspected that these lesions were hemangiomas. No other tumors were found by the imaging studies.

\section{Clinical course}

We strongly suspected the presence of a glucagonoma because she had NME, low aminoacidemia, and a markedly increased serum glucagon level, which are the features of glucagonoma syndrome. However, we only found several liver masses resembling hemangiomas, and did not detect any lesions in pancreas, GI tract, or other organs. Thus, we did not make a diagnosis of glucagonoma. NME improved markedly after intravenous infusion of an amino acid preparation, and her plasma glucose was reduced to around 150-200 $\mathrm{mg} / \mathrm{dl}$ by intensive insulin therapy. However, she still needed insulin treatment after refinement of glucose toxicity, suggesting that her pancreatic $\beta$ cell dysfunction was irreversible. Her general condition gradually deteriorated, and she died of renal failure, pneumonia, 
Table 1. Laboratory Findings

\begin{tabular}{|c|c|c|c|c|c|}
\hline \multicolumn{2}{|l|}{ Urinalysis : } & \multicolumn{2}{|c|}{ Biochemistry : } & \multicolumn{2}{|l|}{ Hormones : } \\
\hline protein & $(3+)$ & T.P. & $6.4 \mathrm{~g} / \mathrm{dl}$ & TSH & $2.43 \mu \mathrm{IU} / \mathrm{ml}$ \\
\hline glucose & $( \pm)$ & $\mathrm{Alb}$ & $2.9 \mathrm{~g} / \mathrm{dl}$ & FT3 & $1.7 \mathrm{~g} / \mathrm{ml}$ \\
\hline \multirow[t]{2}{*}{ ketone bodies } & $(-)$ & T.Bil & $0.3 \mathrm{mg} / \mathrm{dl}$ & FT4 & $1.5 \mathrm{ng} / \mathrm{ml}$ \\
\hline & & AST & $21 \mathrm{IU} / 1$ & EPO & $45.7 \mathrm{U} / \mathrm{ml}$ \\
\hline \multicolumn{2}{|l|}{ Peripheral blood : } & ALT & $32 \mathrm{IU} / 1$ & IRI & $<1.0 \mu \mathrm{U} / \mathrm{ml}$ \\
\hline WBC & $11400 / \mu 1$ & LDH & $201 \mathrm{IU} / 1$ & IRG & $4940 \mathrm{pg} / \mathrm{ml}$ \\
\hline Neutro & $95 \%$ & ALP & $472 \mathrm{IU} / 1$ & U-CPR & $4 \mu \mathrm{g} /$ day \\
\hline Lympho & $3 \%$ & $\gamma$-GTP & $38 \mathrm{IU} / 1$ & & \\
\hline $\mathrm{RBC}$ & $327 \times 10^{4} / \mu 1$ & AMY & $392 \mathrm{IU} / 1$ & Tumor markers : & \\
\hline $\mathrm{Hb}$ & $9.9 \mathrm{~g} / \mathrm{dl}$ & $\mathrm{Cr}$ & $2.89 \mathrm{mg} / \mathrm{dl}$ & CEA & $3.6 \mathrm{ng} / \mathrm{ml}$ \\
\hline $\mathrm{MCV}$ & $94.1 \mathrm{fl}$ & $24 \mathrm{Ccr}$ & $11 \mathrm{ml} / \mathrm{min}$ & AFP & $4.9 \mathrm{ng} / \mathrm{dl}$ \\
\hline Plt & $53.3 \times 10^{4} / \mu 1$ & BUN & $96.9 \mathrm{mg} / \mathrm{dl}$ & CA19-9 & $25.0 \mathrm{U} / \mathrm{ml}$ \\
\hline \multirow[t]{12}{*}{$\operatorname{ESR}(1 \mathrm{~h})$} & $102 \mathrm{~mm}$ & UA & $16.3 \mathrm{mg} / \mathrm{dl}$ & $\mathrm{SCC}$ & $1.2 \mathrm{ng} / \mathrm{ml}$ \\
\hline & & $\mathrm{Na}$ & $135 \mathrm{mEq} / 1$ & CA125 & $15.4 \mathrm{U} / \mathrm{ml}$ \\
\hline & & K & $5.5 \mathrm{mEq} / 1$ & GAD antibody & $<0.4 \mathrm{U} / \mathrm{ml}$ \\
\hline & & $\mathrm{Cl}$ & $97 \mathrm{mEq} / 1$ & & \\
\hline & & $\mathrm{TC}$ & $190 \mathrm{mg} / \mathrm{dl}$ & & \\
\hline & & HDL-C & $55 \mathrm{mg} / \mathrm{dl}$ & & \\
\hline & & LDL-C & $107 \mathrm{mg} / \mathrm{dl}$ & & \\
\hline & & TG & $116 \mathrm{mg} / \mathrm{dl}$ & & \\
\hline & & PPPG & $284 \mathrm{mg} / \mathrm{dl}$ & & \\
\hline & & $\mathrm{HbA} 1 \mathrm{c}$ & $7.10 \%$ & & \\
\hline & & GA & $34.90 \%$ & & \\
\hline & & CRP & $4.17 \mathrm{mg} / \mathrm{dl}$ & & \\
\hline
\end{tabular}

and disseminated intravascular coagulation on day 57 after hospitalization.

\section{Findings at autopsy}

As shown in Figure 1, the mass in the left lobe of the liver was a large solid tumor $(8 \times 6 \times 5 \mathrm{~cm})$ with a pattern of white and dark brown stripes, while the two white nodules (1.2 and $1.0 \mathrm{~cm}$ in diameter) in the right lobe were also similar. Although the pancreas, the anastomosed gastroduodenum after surgery, the small bowel, and both kidneys were carefully examined, no tumor was identified.

\section{Histopathological and immunohistochemical findings}

As shown in Figure 2, hematoxylin and eosin staining of sections from the left lobe tumor demonstrated that the tumor cells mainly formed cords or showed a cobblestone pattern. There was moderate nuclear atypia and 2-5 mitoses per $2 \mathrm{~mm}^{2}$ [10 high power fields (HPF) $40 \times$ magnification], as well as infiltrates, hem- orrhage, and necrosis. However, the Ki-67 (MIB-1) labeling index obtained by immunostaining showed low proliferative activity (only $1-2 \%$ of the cells were positive). These histopathological findings matched the characteristics of neuroendocrine carcinoma [1]. Furthermore, the tumor cells were positive for glucagon, the neuroendocrine cell marker chromogranin A, and two other neuroendocrine cell markers synaptophysin and Grimelius. The same findings were also observed in the nodules from the right lobe, indicating a diagnosis of malignant hepatic glucagonoma with intrahepatic metastases.

\section{Discussion}

Glucagonoma syndrome is a rare but well-defined clinical entity that is caused by the overproduction of glucagon from a pancreatic islet cell tumor. In typical cases, diagnosis is usually not difficult. In this patient, however, there was no tumor mass except for liver lesions that resembled hemangiomas. NME only oc- 
$\mathbf{A}$

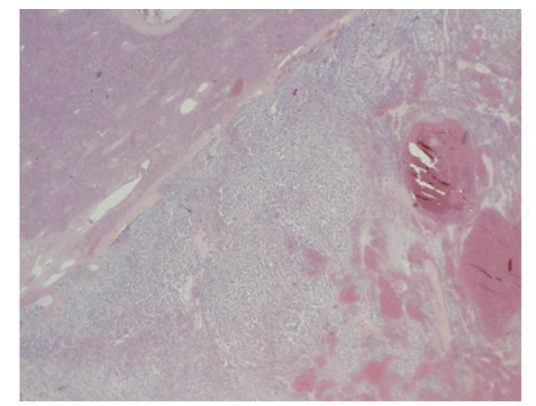

C

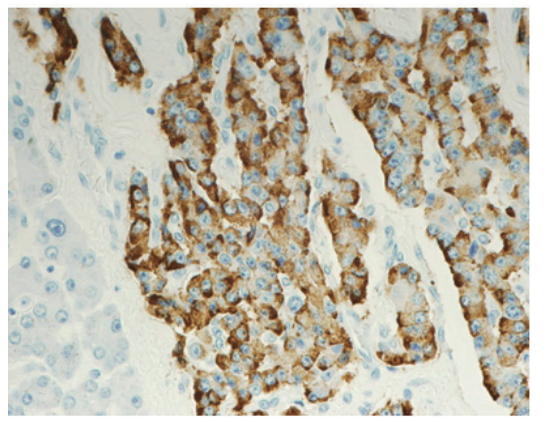

B

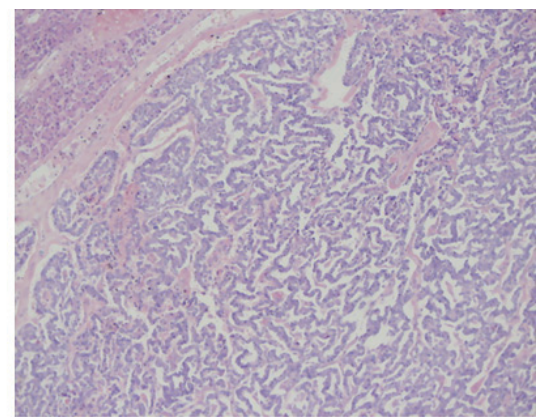

D

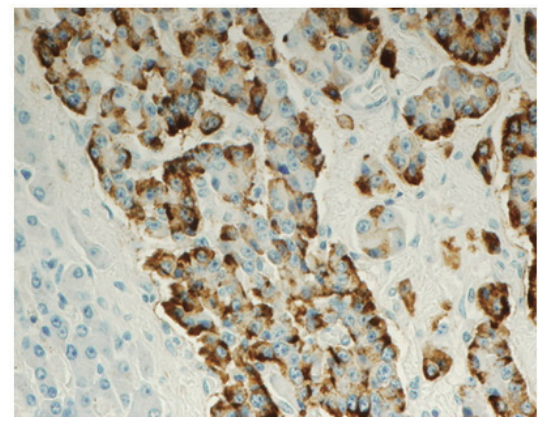

Fig. 2. Histopathological findings.

Hematoxylin and eosin staining demonstrates that the tumor is mainly composed of cell cords and layers with a cobblestone appearance. The cells have moderate nuclear atypia and 2-5 mitoses cells per $2 \mathrm{~mm}^{2}$ [10 high power fields (HPF) $40 \times$ magnification]. There is also infiltration, hemorrhage, and necrosis. A: 20×; B: 200×. The tumour cells are positive for the neuroendocrine cell marker chromogranin (C: 400×) and glucagon (D: 400×).

curs in approximately $50 \%$ of glucagonoma patients $[5,6]$, but this symptom is highly suggestive of the syndrome. Low aminoacidemia also has diagnostic value because it is observed in almost all cases of glucagonoma. While diabetes mellitus, impaired glucose tolerance $(88.4 \%)$, weight loss $(76.6 \%)$, and anemia (73.4\%) are frequent in glucagonoma syndrome [6], these are nonspecific symptoms. Regarding the site of glucagonoma, 397 patients $(97.3 \%)$ in a series of 407 patients had their tumors in the pancreas. Three patients $(0.7 \%)$ had documented extrapancreatic lesions (one each in the kidney [7], duodenum [8], and lung [9]), and the primary site was not described in seven (1.7\%) [2]. Endocrine cell carcinomas in patients with NET usually arise in the gastrointestinal tract, whereas primary involvement of the liver is very rare, but gut and pancreatic NETs can easily metastasize to the liver. Based on this background, we considered whether the malignant hepatic glucagonoma in this patient was a primary or metastatic tumor. We examined tissues that are frequently affected by glucagonoma and NET (pancreas and gut) and tissues that are sometimes affected (kidneys and lungs), but no tumor was detect- ed in any of these organs at autopsy. Finally, there is a possibility that the liver mass was a metastasis from the gastroduodenal lesion resected at the age of 63 years. It has been reported that the characteristics of primary hepatic NET are as follows: 1) these are comparatively large tumors (a maximum diameter of more than $10 \mathrm{~cm}$ is not rare), 2) intrahepatic/extrahepatic metastasis or invasion of surrounding tissues is common, 3) the prognosis is poor, 4) cirrhosis is absent, and 5) histologically there is scattered necrosis with nuclear atypia and more than 2-3 mitoses per $2 \mathrm{~mm}^{2}$ [10 high power fields (HPF) $40 \times$ magnification] [1014]. Because our case matched these characteristics described above, we diagnosed this case as primary malignant hepatic glucagonoma and not metastasis.

According to Ozaki et al. [3] and Yasuda et al. [4], primary hepatic neuroendocrine carcinomas were only identified in around 40 patients worldwide up to 2007. Although some of these tumors secreted hormones such as ACTH [15], somatostatin, gastrin [14, 16], pancreatic polypeptide [16], and serotonin [12], few patients had any symptoms. In our literature search, we were not able to find another report of primary ma- 
lignant hepatic glucagonoma. The reason for the low proliferative activity in Ki 67 labeling index may be that the specimen was prepared several hours posthumously. NET can be treated by somatostatin analog therapy because of being associated with overexpression of the somatostatin receptor (SSTR). Octreotide acetate is a recently introduced somatostatin analogue that has a high efficacy when tumors express SSTR-2, in particular, and our patient's tumor expressed SSTR-2 and -5 . Thus, efficacy of somatosta- tin analog therapy could have been expected in this case. Unfortunately, we missed the chance to administer somatostatin analogue, because a definitive diagnosis with malignant hepatic glucagonoma was not made before autopsy and her general condition deteriorated progressively.

In conclusion, we reported a case of primary malignant hepatic glucagonoma together with the histopathological findings at autopsy.

\section{References}

1. Klöppel G, Perren A, Heitz PU (2004) The gastroenteropancreatic neuroendocrine cell system and its tumors: the WHO classification. Ann N Y Acad Sci 1014: 13-27.

2. Soga J, Yakuwa Y (1998) Glucagonomas/diabeticodermatogenic syndrome (DDS): a statistical evaluation of 407 reported cases. $J$ Hepatobiliary Pancreat Surg 5: 312-319.

3. Ozaki T, Kaibori M, Koike Y, Uemura Y, Seki T, Kamiyama Y (2007) Primary hepatic neuroendocrine carcinoma: a hepatectomy case report. Journal of Clinical Surgery 62: 553-557 (in Japanese).

4. Yasuda E, Takeshita M, Murata S, Ihaku Y, Nitta T, Akutagawa H, Egashira Y, Shibayama Y (2006) Neuroendocrine carcinoma of the liver associated with dermatomyositis: autopsy case and review of the literature. Pathol Int 56: 749-754.

5. van Beek AP, de Haas ER, van Vloten WA, Lips CJ, Roijers JF, Canninga-van Dijk MR (2004) The glucagonoma syndrome and necrolytic migratory erythema: a clinical review. Eur J Endocrinol 151: 531-537.

6. Tanaka K, Toriumi M, Ito Y, Ogino Y, Noguchi K, Osada M (1996) Glucagonoma syndrome and glucagon-producing tumors. Journal of Biliary Tract \& Pancreas 17: 33-42 (in Japanese).

7. Gleeson MH, Bloom SR, Polak JM, Henry K, Dowling RH (1971) Endocrine tumour in kidney affecting small bowel structure, motility, and absorptive function. Gut 12: 773-782.

8. Roggli VL, Judge DM, McGavran MH (1979) Duodenal glucagonoma: A case report. Hum Pathol 10: 350-353.
9. Hunstein W, Trumper LH, Dummer R, Schwechheimer K (1988) Glucagonoma syndrome and bronchial carcinoma. Ann Intern Med 109: 920-921.

10. Hsuen C, Tan XD (1993) Primary hepatic neuroendocrine carcinoma in a child: morphologic, immunocytochemical, and molecular biologic studies. Cancer 71: 2660-2665.

11. Yasoshima H, Uematsu K, Sakurai K, Ueno Y, Hori K, Kanazawa N, Tanaka T, Yamanaka N, Okamoto E (1993) Primary hepatic carcinoid tumor. Acta Pathol Jpn 43: 783-789.

12. Pilichowska M, Kimura N, Ouchi A, Lin H, Mizuno Y, Nagura H (1999) Primary hepatic carcinoid and neuroendocrine carcinoma: Clinicopathological and immunohistochemical study of five cases. Pathol Int 49: 318-324.

13. Asakawa T, Tomioka T, Abe K, Yamaguchi T, Tsunoda T, Kanematsu T (1999) Primary hepatic carcinoid tumor. J Gastroenterol 34: 123-127.

14. Krishnamurthy SC, Dutta V, Pai SA, Kane SV, Jagannath P, Desouza LJ, Deshpande R, Desai PB (1996) Primary carcinoid tumor of the liver: report of four resected cases including one with gastrin production. J Surg Oncol 62: 218-221.

15. Shah NA, Urusova IA, D'Agnolo A, Colquhoun SD, Rosenbloom BE, Vener SL, Geller SA, Younes M, Lechago J, Heaney AP (2007) Primary hepatic carcinoid tumor presenting as Cushing's syndrome. $J$ Endocrinol Invest 30: 327-333.

16. Xi YP, Yu JY (1986) Primary neuroendocrine carcinoma of the liver. Ultrastruct Pathol 10: 331-336. 